Ann. Biol. anim. Bioch. Biophys., I968, 8 (I), 45-67.

\title{
INFLUENCE DE QUELQUES TECHNIQUES DE CONSERVATION SUR L'EFFICACITÉ DE L'AZOTE DE LA LUZERNE CHEZ LE MOUTON
}

\author{
Michelle DURAND, S.-Z. ZELTER, J.-L. TISSERAND \\ avec la collaboration technique de \\ Monique Porsson, F. DE Monredon, Annie Barde, Christiane Dumay \\ Laboratoire de Recherches sur la Conservation et l'Efficacité des Aliments, \\ 16, rue Claude-Bernard, Paris $5 \mathrm{e}$ \\ Centre national de Recherches zootechniques, \\ Institut national de la Recherche agronomique
}

\section{SOMMAIRE}

Trois séries d'expériences sont effectuées en 1963-64-65, avec des moutons adultes à l'entretien, dont certains sont munis de canules permanentes de rumen. Leur objectif est de comparer la valeur azotée d'un fourrage de luzerne conservé selon différentes techniques : congélation du vert, fenaison partielle suivie d'un post-séchage en grange, ensilage humide sans traitement, ensilage au métabisulfite de sodium ou à l'acide A.I.V., ensilage par préfanage $\left(35^{-40} \mathrm{p}\right.$. Ioo de matière sèche). Tous les traitements sont appliqués le même jour à la même coupe de fourrage.

Les critères biologiques retenus sont : évolution postprandiale de l'ammoniogenèse et de la concentration en azote non protéique dans le rumen, de l'urée du sang périphérique, digestibilité et rétention azotées.

Les points suivants se dégagent des résultats :

- le préfanage améliore nettement l'efficacité azotée de l'ensilage de luzerne en la rendant comparable à celle du vert congelé et du foin préparés à partir de la même coupe (tabl. 4);

- les catabolismes glucidique et azoté que subit en général une luzerne ensilée à faible taux de matière sèche et sans acidification préalable, amoindrissent fortement la valeur azotée de l'ensilage au point d'entraîner parfois des bilans azotés négatifs, même lorsque l'ingéré azoté dépasse largement les besoins théoriques de l'animal (tabl. 4 et 9 );

- la distribution simultanée d'un aliment énergétique susceptible d'activer la protéosynthèse bactérienne dans le rumen à partir de formes azotées particulièrement dégradées $\left(\mathrm{NH}_{3}\right)$ améliore fortement l'utilisation azotée d'un mauvais ensilage (tabl. 9 et ro).

\section{INTRODUCTION}

Des recherches antérieures soulignent l'importance des modifications chimiques qui surviennent au cours de la conservation d'une luzerne selon différentes techniques d'ensilage et les difficultés d'éviter les dégradations des protéines du fourrage : contrai- 
rement à l'addition d'acides minéraux AIV, celle de métabisulfite de sodium ne semble inhiber ni la protéolyse, ni l'ammoniogenèse (DURAND-SALOMON et ZELTER, I960) ; une élévation de la matière sèche à une teneur voisine de $35 \mathrm{p}$. Ioo par préfanage sur champ, limite l'ampleur des processus de désamination mais a peu d'action sur la protéolyse (GouEt et al, I965). Or, il est bien connu (ANnison et al, I954), qu'une solubilité élevée des protéines s'accompagne souvent d'une intense ammoniogenèse au niveau du rumen suivie d'une excrétion azotée urinaire élevée.

Les modifications chimiques susceptibles d'intervenir au cours de la conservation ayant toute chance de se répercuter sur la valeur azotée, nous avons étudié l'influence comparée de plusieurs techniques de conservation de la luzerne sur diverses étapes du métabolisme azoté et sur l'efficacité azotée de ce fourrage chez le mouton.

Dans une première série d'expériences réalisées au laboratoire en I96I-I962, ShINN (I963) distribue de la luzerne conservée de différentes manières, simultanément avec un aliment énergétique pauvre en azote pour ajuster l'apport azoté au niveau du besoin théorique du mouton adulte à l'entretien. Aucun écart significatif n'est décelé entre les valeurs azotées des divers types de fourrages conservés (foin, ensilage au métabisulfite de sodium, ensilage préfané) malgré des différences qualitatives importantes entre les aliments. On peut supposer que la présence d'amidon dans l'aliment énergétique avait pu masquer l'effet intrinsèque des traitements technologiques en améliorant l'utilisation dans le rumen de l'ammoniaque des ensilages mal conservés pour la protéosynthèse bactérienne.

Une dissociation expérimentale de l'action de ces deux facteurs interférents pouvait présenter de l'intérêt pour préciser les incidences propres aux traitements de conservation. Nous avons repris les recherches en distribuant les fourrages conservés seuls, puis associés à un aliment complémentaire énergétique dépourvu d'amidon.

\section{MATÉRIEI, ET MÉTHODES EXPÉRIMENTALES}

\section{$I^{\circ}$ Dispositifs et critères expérimentaux}

Trois séries d'expériences $(\mathrm{A}, \mathrm{B}, \mathrm{C})$ sont réalisées avec de la luzerne (Medicago sativa) variété Flamande récoltée à un stade de floraison de 5 -10 p. 100 en 1963 ( $2^{\mathrm{e}}$ coupe), 1964 ( $\mathrm{I}^{\mathrm{re}}$ coupe) et $\mathrm{I} 965$ $\left(2^{\mathbf{e}}\right.$ coupe). Dans deux de ces séries la valeur azotée de différents types d'ensilage est comparée à celles du vert congelé et du foin ventilé (série $A$ ), ou à celle du foin ventilé (série B) dans des régimes comportant uniquement le fourrage conservé étudié. Dans la troisième (série C) l'efficacité azotée d'ensilage préfané et d'ensilage humide non traité est mesurée en régime fourrage seul, et en régime mixte (fourrage + complément énergétique).

Pour chacun des essais, tous les traitements de conservation sont appliqués le même jour à de la luzerne de même provenance (coupe et parcelle). Les méthodes d'ensilage utilisées sont décrites par FatianofF et al. (1966). Le foin est fabriqué par préfanage suivi d'un post-séchage en grange par ventilation forcée avec de l'air ambiant ; la plante stockée à l'état de vert est congelée en tunnel et conservée à $-18^{\circ} \mathrm{C}$.

Les dispositifs généraux et les critères des 3 expériences sont donnés dans le tableau $\mathbf{r}$.

Dans les expériences $A$ et $C$, les animaux reçoivent les différents aliments en quantité calculée pour assurer la couverture de leurs besoins énergétiques selon les normes de LEROY (I 96I).

Dans l'expérience $B$, l'ensilage AIV étant l'aliment le moins bien accepté, les quantités journalières de matière sèche distribuées avec les deux autres régimes sont ajustées sur celles consommées avec le premier; elles couvrent environ 80 p. 100 des besoins énergétiques théoriques. 
VAI,EUR AZOTÉE COMPARÉE DE LUZERNES CONSERVÉES
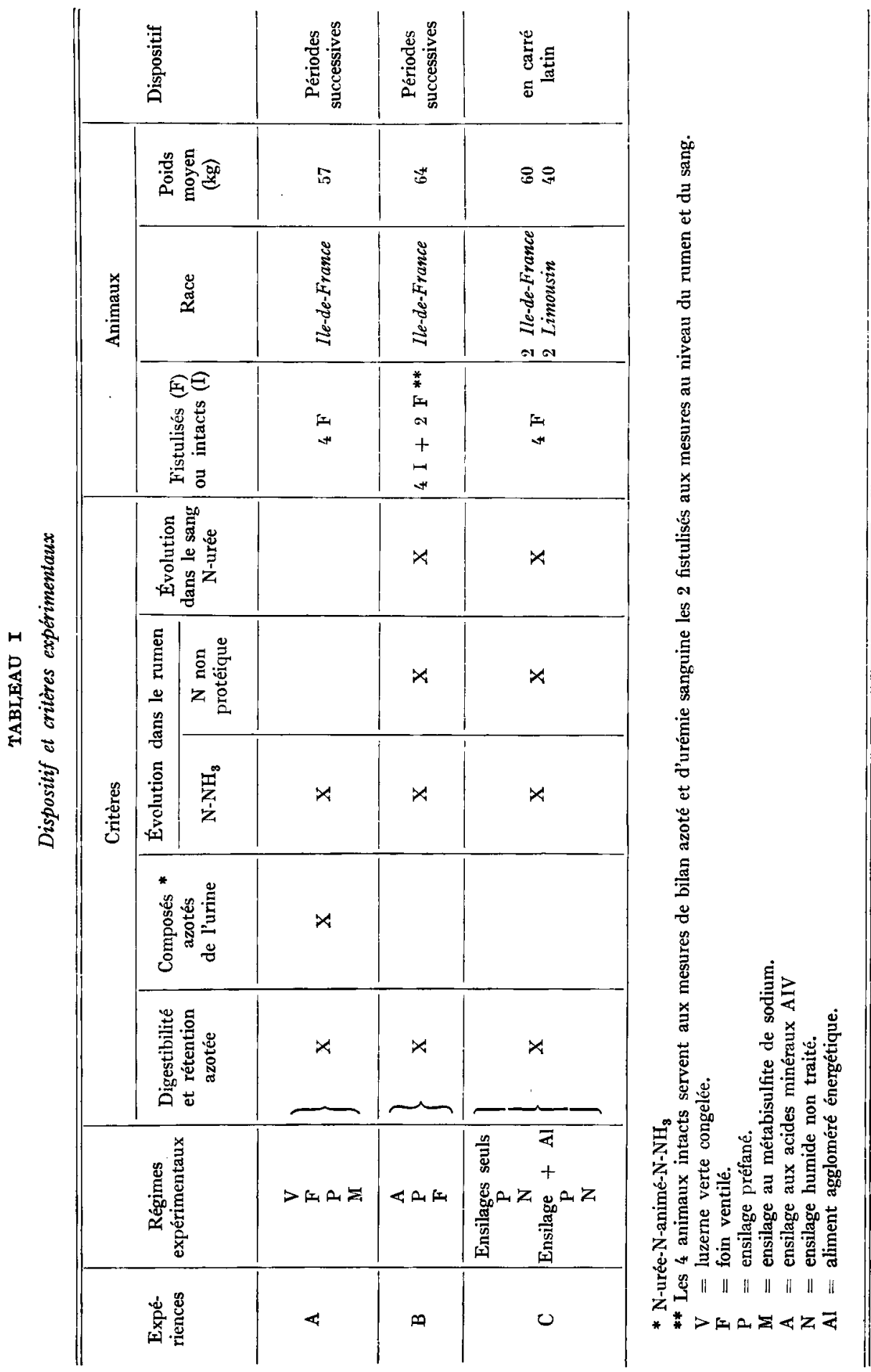
Dans l'expérience $C$, les deux ensilages sont donnés seuls ou avec un aliment énergétique complémentaire. Celui-ci pauvre en azote (matière azotée $=6,4$ p. roo de la M.S.) abaisse l'apport azoté de la ration au niveau du besoin théorique, tout en maintenant un apport énergétique correct. Il est composé de paille de blé (44,5 $\mathrm{p}$. 100) de pulpes sèches de betterave (47 p. roo), d'huile de maîs ( $5 \mathrm{p}$. 100) et de matière minérale $(3,5 \mathrm{p}$. I00). Dans le régime mixte, la proportion de matière sèche d'ensilage diffère avec la taille des sujets (tabl. 2 ).

\section{TABLEAU 2}

Expérience $C$

Quantité de matière sèche distribuée par jour sous forme d'ensilage et d'aliment énergétique complémentaire

(M.S. g/jour)

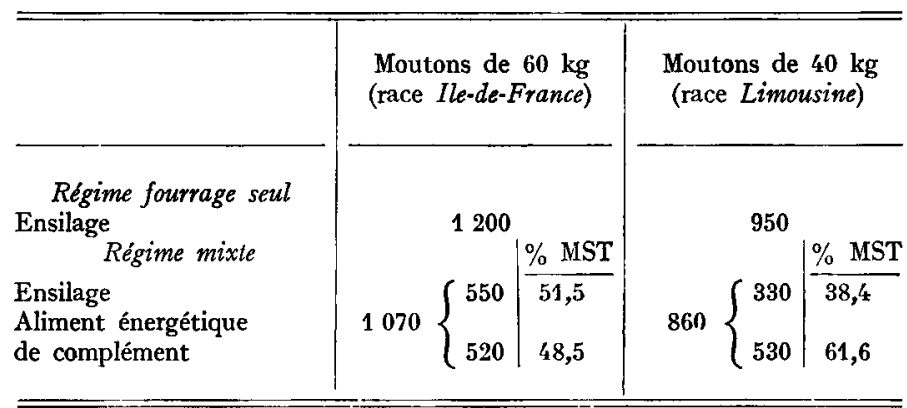

\section{$2^{\circ}$ Méthodes biologiques}

\section{a) Bilan azoté.}

Les périodes d'adaptation à chaque régime sont de 20 jours (les animaux sont maintenus pendant I 5 jours au sol et les 5 jours suivants en cage). Les mesures de bilan portent sur les ro jours qui suivent. Les animaux sont équipés d'un dispositif permettant de recueillir l'urine séparément des fèces dans des flacons contenant de l'acide sulfurique et du thymol pour éviter des contaminations et des pertes d'ammoniac (ZELTER et ChARLET-LÉRY, I96I). Les ingesta et excreta frais sont mesurés et échantillonnés chaque jour. Une partie aliquote est conservée au congélateur $\left(-18^{\circ} \mathrm{C}\right)$ en vue des dosages d'azote, effectués sur des échantillons frais pondérés cumulés, par période de 5 jours.

La teneur des ingesta et des matières fécales en matière sèche est déterminée journellement. Un dosage de matières minérales est effectué sur les échantillons secs cumulés de la période de bilan, en vue du calcul de la matière organique digestible.

\section{b) Mesures au niveau du rumen.}

Des prélèvements de jus de rumen sont effectués à l'issue des périodes de bilan azoté pendant deux jours non consécutifs pour les expériences $\mathrm{A}$ et $\mathrm{C}$ et pendant une seule journée pour l'expérience $B$. Les temps de prélèvement sont situés dans l'intervalle o- 7 heures après le repas du matin ( $\mathrm{I} / 2$ ration journalière), en général aux temps $\mathrm{o}, \mathrm{I}, 2,3,4,5,7$ heures. Le contenu prélevé (environ $20 \mathrm{~g}$ ) est filtré aussitôt sur 5 épaisseurs de gaze. I heure après le repas (expérience $\mathrm{B}$ et $\mathrm{C}$ ), ro g de polyéthylène glycol (PEG) solubilisés dans Ioo $\mathrm{ml}$ d'eau, sont introduits dans le rumen afin d'évaluer le volume de son contenu à ce temps, suivant la technique de HYDEN (I96I).

Dans l'expérience $\mathrm{A}$, la $\mathrm{r} / 2$ de la ration journalière de fourrage est à la disposition de l'animal, pendant toute la durée des prélèvements. Dans les expériences $B$ et $C$ les refus non consommés I heure après le début du repas sont retirés et pesés. L'eau de boisson est totalement supprimée pendant les prélèvements dès le début du repas dans les expériences $A$ et $C$, et retirée I heure après le début du repas dans l'expérience $B$.

\section{c) Mesure de l'urée sanguine.}

Des prises de sang sont faites dans la veine jugulaire aux temps o- $3-5$ et 7 heures après le début du repas du matin, pendant 2 jours non consécutifs dans l'expérience C. Dans l'expérience B, elles ont lieu le jour des prélèvements de jus de rumen sur animaux fistulisés et le dernier jour de la période de bilan azoté sur les animaux intacts. 
d) Techniques analytiques.

L'analyse qualitative des ensilages est faite par les techniques décrites dans GouET et al. (I965). L'azote soluble total est extrait par broyage de l'échantillon dans la salive artificielle (MAC DoUGALL) utilisée par TISSERAND et ZELTER (I965).

L'azote total des aliments, de l'urine et des fèces est dosé selon Kjeldahl (catalyseur : oxyde rouge de mercure, microdistillation dans l'appareil Parnas-Wagner, distillat recueilli dans une solution d'acide borique à I $\mathrm{p}$. Too et titrée par $\mathrm{SO}_{4} \mathrm{H}_{2} \mathrm{~N} / 50$ en présence de l'indicateur de Conway.). L'urée est déterminée dans l'urine par la méthode colorimétrique de SHRAmm et AINEs (1959) et dans le sang immédiatement après prélèvement par la technique à l'uréase CoNwAY (I950). L'azote aminé libre total des ensilages et de l'urine est dosé suivant la méthode au cuivre par photométrie après réaction à la cuprizone MALANGEAU et BouRdon, (I963). Le dosage de l'ammoniaque est fait selon CONWAY (I950) dans l'urine et dans le jus de panse dans les 5 minutes qui suivent le prélèvement $\mathrm{N}$ non protéique est déterminé par précipitation à l'acide trichloracétique (concentration finale de $\mathrm{TCA}=$ Io $\mathrm{p}$. Ioo), suivie d'une centrifugation à 18 ooo $\mathrm{g}$. Le polyéthylène glycol est dosé par turbidimétrie selon HYDEN (1955).

\section{RÉSULTATS}

La composition chimique des fourrages et leur qualité sont données dans le tableau 3 .

\section{Io Comparaison des régimes luzerne verte congelée, foin ventilé, ensilage préfané et ensilage traité au métabisulfite de sodium}

(Expérience A)

Les résultats rapportés dans le tableau 4 concernent la moyenne des résultats individuels obtenus avec chaque régime. Un animal a dû être éliminé du régime luzerne verte congelée. Les ingesta (tabl. 4) sont légèrement plus importants pour 1a luzerne congelée tant en ce qui concerne 1'azote que la matière organique digestible. Pour les 3 autres régimes les différences ne sont pas significatives mais pour l'ensilage au métabisulfite qui est le moins appétent, les ingesta sont plus faibles; dans ce cas les besoins énergétiques théoriques sont couverts à $80 \mathrm{p}$. Ioo seulement et les besoins azotés à $\mathrm{I} 8 \mathrm{o}$ p. Ioo.

Par rapport à la luzerne verte congelée, les ensilages et surtout le foin ventilé ont des taux de cellulose brute légèrement plus élevés ; 1a teneur en matière organique digestible de ces fourrages est de ce fait inférieure d'environ 6 points. Les taux de matière azotée totale des 4 fourrages est similaire mais la composition de la fracsion azotée des ensilages se distingue de celle du foin et du vert congelé par des proportions plus élevées de $\mathrm{N}$ soluble, de $\mathrm{N}$ non protéique et de $\mathrm{N}-\mathrm{NH}_{3}$ : ces formes azotées sont en quantités plus importantes dans l'ensilage au métabisulfite, qui par ailleurs contient davantage d'acide acétique et d'acide butyrique, indices d'une mauvaise conservation.

\section{Intensité de l'ammoniogenèse au niveau du rumen (fig. I).}

Pour des ingesta azotés voisins, l'augmentation des concentrations ammoniacales rapportées à celle du temps o est nettement plus faible pour le foin que pour les ensilages ; ce phénomène est particulièrement net chez le mouton 42. La consom- 
M. DURAND, S.-Z. ZELTER, J.-L. TISSERAND

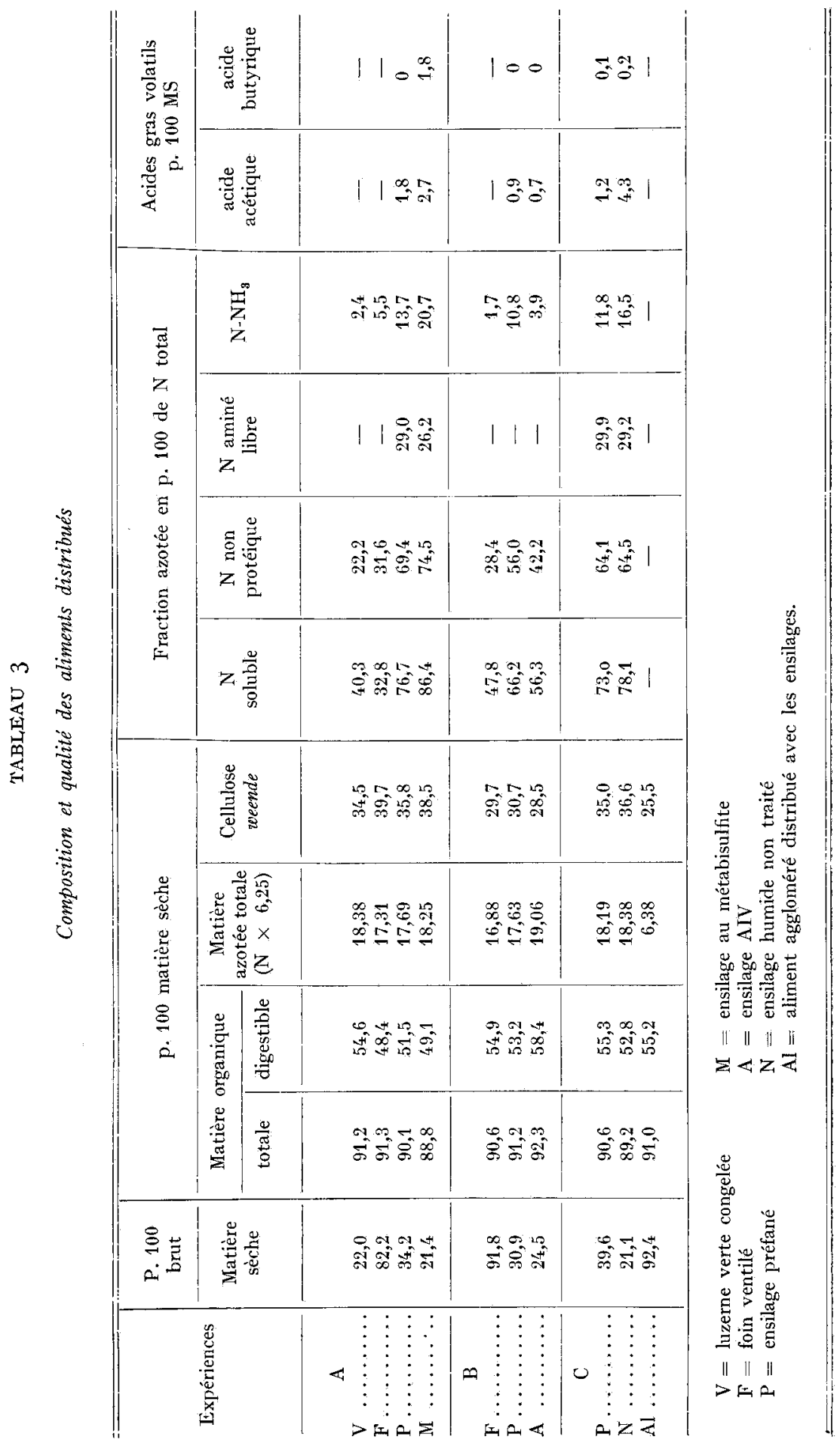




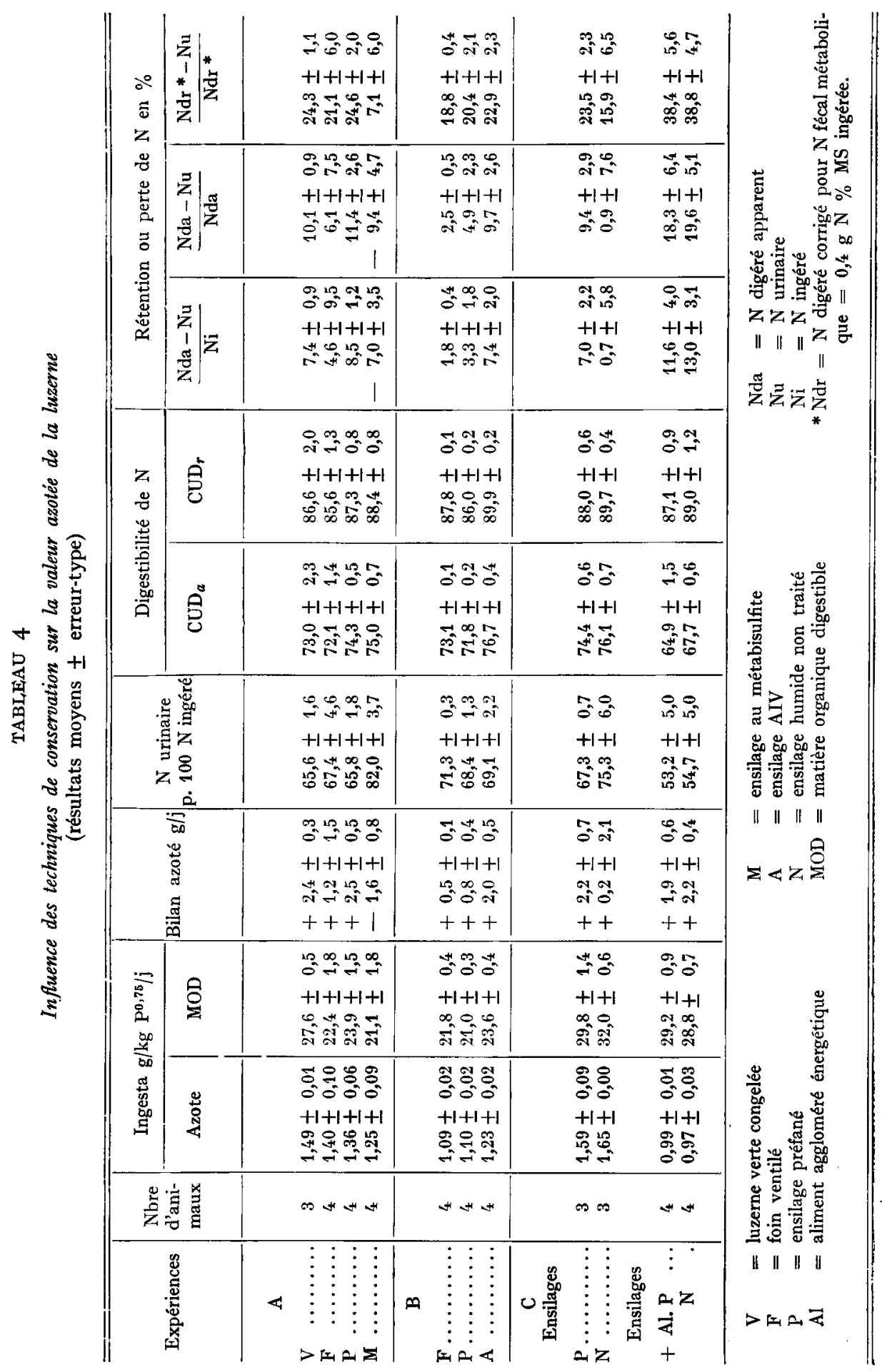


mation d'ensilage préfané fournit les concentrations les plus élevées de $\mathrm{NH}_{3}$ dans le rumen. Le mouton 25 ayant consommé plus lentement le repas d'ensilage aut métabistulfite, l'ammoniogenèse correspondante est plus étalée dans le temps.

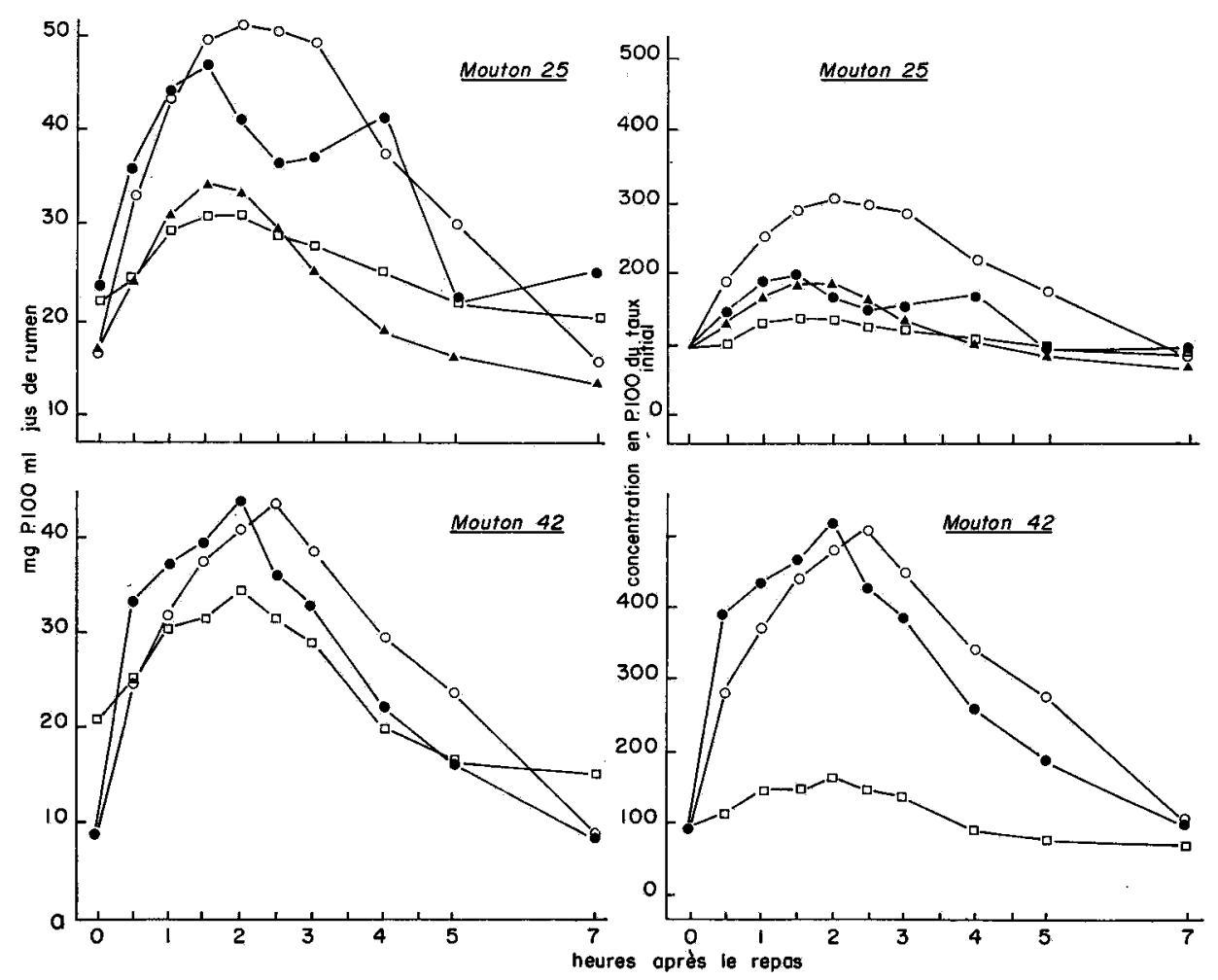

FIG. I. - Expérience $A$

Formation de $\mathrm{N}-\mathrm{NH}_{3}$ au niveau du rumen après le repas du matin Aert congelé
- foin
- ensilage au métabisulfite
ensilage préfané

$\begin{array}{lll}\text { Mouton 25 } & \text { N ingéré (g) } \\ & \bullet & 13,9 \\ & \bullet & \text { I6,2 } \\ & \bullet & 15,0 \\ \text { Mouton 42 } & \circ & \text { I5,9 } \\ & \square & \text { I I,6 } \\ & \bullet & 12,6 \\ & \circ & \text { II,2 }\end{array}$

\section{Digestibilité et rétention azotée.}

La tendance des résultats est la même, quel que soit le mode d'expression du coefficient de digestibilité, apparent ou réel (corrigé pour $\mathrm{N}$ fécal métabolique $=0,4 \mathrm{~g}$ $\mathrm{N} \mathrm{p}$. roo $\mathrm{g}$ de matière sèche ingérée) : les ensilages, surtout l'ensilage au métabisulfite, ont une digestibilité azotée supérieure à celle du foin, mais les différences ne sont pas significatives.

Les bilans azotés des régimes de luzerne verte congelée, de foin et d'ensilage préfané sont similaires et tous positifs. L'ensilage au métabisulfite entraîne systé- 
matiquement des bilans négatifs pour tous les animaux. Avec cet ensilage l'excrétion de $\mathrm{N}$ urinaire rapportée à $\mathrm{N}$ ingéré est de $30 \mathrm{p}$. Ioo supérieure à celle des autres régimes. L'azote retenu rapporté à $\mathrm{N}$ ingéré, digéré apparent ou digéré réel, n'accuse pas de différences entre vert congelé, foin et ensilage préfané ; par contre les coefficients de rétention de l'ensilage au métabisulfite sont significativement plus faibles $(\mathrm{P}<0,05)$, malgré des variations individuelles importantes.

Les proportions de $\mathrm{N}$ uréique, de $\mathrm{N}$ ammoniacal et de $\mathrm{N}$ aminé libre de l'urine, ne sont pas modifiées par le type de régime (tab1. 5) : les teneurs en $\mathrm{N}$ aminé et $\mathrm{N}-\mathrm{NH}_{3}$ sont faibles ( $\mathrm{N}$ aminé $<\mathrm{I}$ p. roo du $\mathrm{N}$ total, $\mathrm{N}-\mathrm{NH}_{\mathbf{3}}<3 \mathrm{p}$. Ioo) ; et l'azote uréique représente en moyenne $80 \mathrm{p}$. roo du $\mathrm{N}$ total. L'excrétion supplémentaire de $\mathrm{N}$ urinaire avec l'ensilage au métabisulfite a essentiellement lieu sous forme d'urée (tabl. 5).

TABLEAU 5

Constituants azotés de l'urine

Expérience $A$

(moyenne \pm erreur-type)

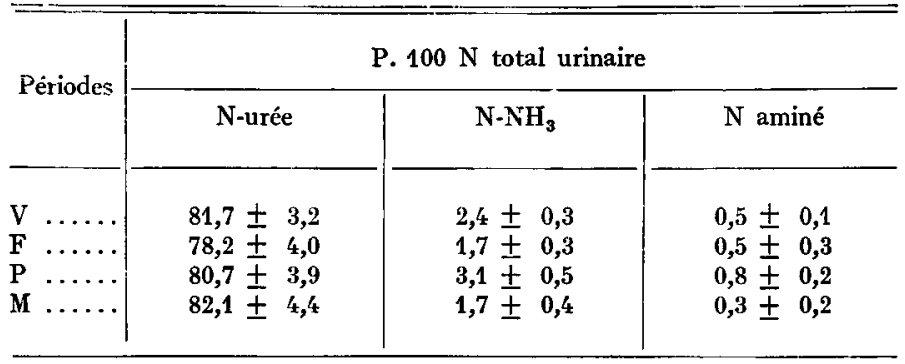

$\mathrm{V}=$ luzerne verte congelée

$\mathrm{F}=$ foin ventilé

$\mathbf{P}=$ ensilage préfané

$\mathrm{M}=$ ensilage au métabisulfite.

$2^{\circ}$ Comparaison des régimes foin ventilé, ensilage préfané et ensilage AIV (Expérience B)

D'après les tests biochimiques de qualité, les deux ensilages sont parfaitement réussis : absence d'acide butyrique, ammoniogenèse inexistante dans 1'ensilage AIV et très faible dans le préfané qui, par contre, a la couleur et l'odeur d'un ensilage ayant chauffé.

Les animaux fistulisés utilisés uniquement pour les mesures au niveau du rumen et du sang, ont des ingesta inférieurs à ceux non fistulisés en bilan d'azote,. Ce fait est particulièrement net pour l'ensilage AIV dont le $\mathrm{pH}$ trop acide $(\mathrm{pH}=3,3)$, entraînait de l'inappétence. 
Les teneurs en matière organique digestible et en matières azotées totales de cet ensilage sont légèrement plus élevées que celles des deux autres fourrages. (tabl. 3).

Ammoniogenèse dans le rumen et évolution de l'urée du sang périphérique.

Les mesures effectuées sur animaux fistulisés (fig. 2), necorrespondent qu'à une seule donnée par période. Elles n'ont donc qu'une valeur indicative.

Les comparaisons entre régimes (fig. 2, tabl. 6) montrent qu'à jeun (temps o), les concentrations de $\mathrm{N}$ non protéique et de $\mathrm{N}-\mathrm{NH}_{3}$ au niveau du rumen et de $\mathrm{N}$-urée du sang sont plus élevées pour le foin. Les teneurs maximum de $\mathrm{N}-\mathrm{NH}_{3}$ observées 2 heures après le repas sont semblables pour le foin et l'ensilage préfané ; celles de $\mathrm{N}$ non protéique sont $\mathrm{I}$ heure après le repas plus élevées pour le second. Mais l'accroissement des concentrations ammoniacales rapporté au temps o est nettement plus

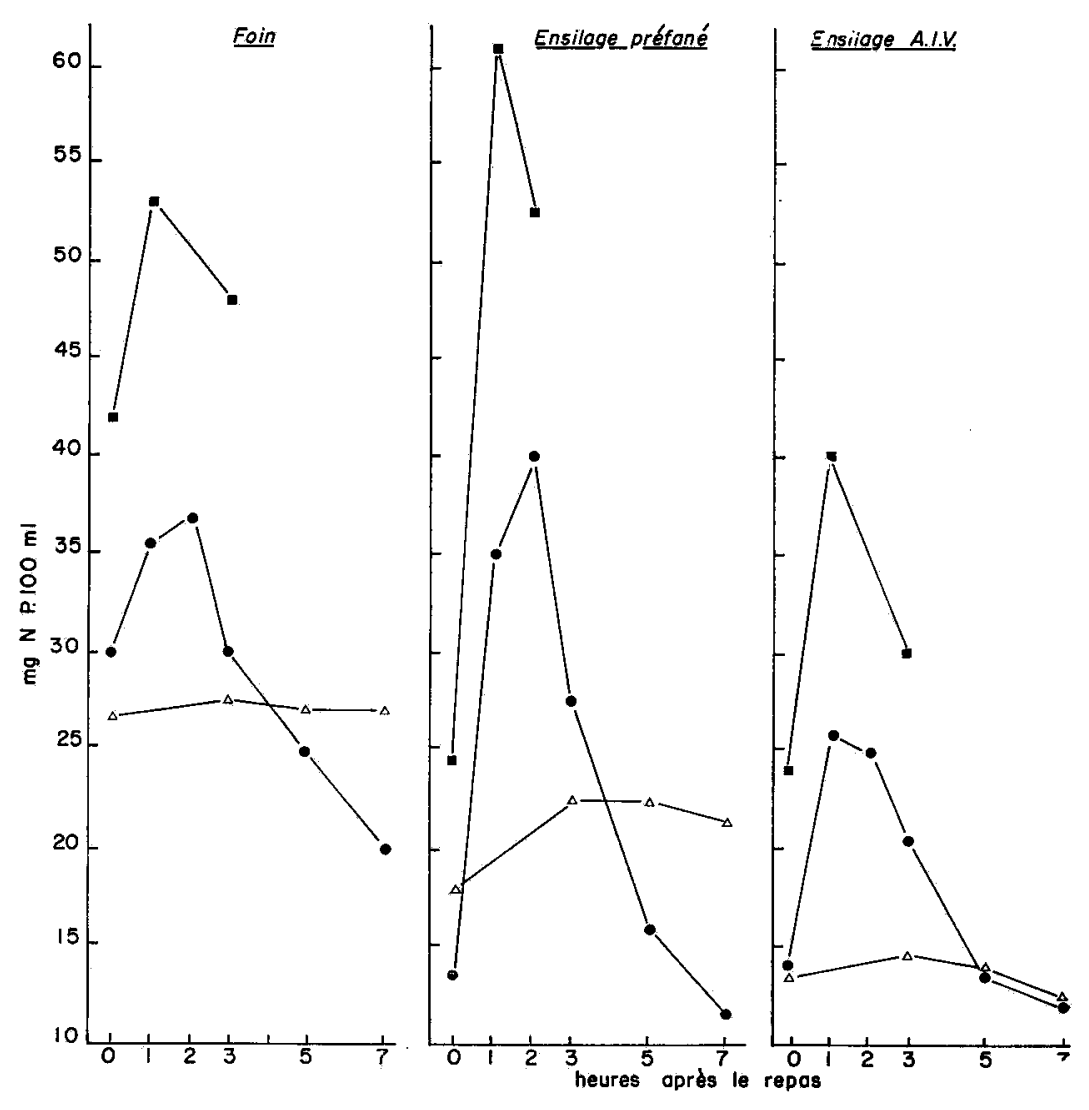

FIG. 2. - Expérience $B$

Evolution postprandiale de $N-N_{3}$ et $N$ non protéique dans le rumen et de $N$ urée du sang périphérique (mg $\mathrm{p}$. I $00 \mathrm{ml}$ )

- $\mathrm{N}-\mathrm{NH}_{3}$

- N non protéique

$\triangle N$ urée sanguine
FoinEnsilage préfané g $\mathrm{N}$ ingéré 10,4 Ensilage A. I. V. g N ingéré 8,7 
fort pour l'ensilage préfané ( $82 \mathrm{p}$. I00), intermédiaire pour l'ensilage AIV (75 p. IOo) et faible pour le foin (24 p. IOo).

\section{TABLEAU 6}

Évolution de l'urée du sang périphérique après le repas du matin Expérience $B$

(résultats moyens \pm erreur-type sur les 4 animaux en bilan azoté)

\begin{tabular}{|c|c|c|c|}
\hline \multirow{2}{*}{ Heures } & \multicolumn{3}{|c|}{$\mathrm{mg} \mathrm{N} \% \mathrm{ml}$ sang } \\
\hline & $\begin{array}{c}\text { Foin ventilé } \\
\left(\mathrm{Ni}^{*}=12,2 \mathrm{~g} \pm 0,2\right)\end{array}$ & $\begin{array}{c}\text { Ensilage préfané } \\
(\mathrm{Ni}=12,0 \mathrm{~g} \pm 0,4)\end{array}$ & $\begin{array}{c}\text { Ensilage AIV } \\
(\mathrm{Ni}=16,8 \mathrm{~g} \pm 0,4)\end{array}$ \\
\hline 0 & $25,0 \pm 0,2$ & $19,0 \pm 1,0$ & $21,8 \pm 0,9$ \\
\hline 3 & $27,4 \pm 0,4$ & $22,9 \pm 1,2$ & $22,4 \pm 1,3$ \\
\hline 5 & $27,1 \pm 0,2$ & $23,5+1,1$ & $24,0 \pm 0,9$ \\
\hline 7 & $25,8 \pm 0,1$ & $22,4 \pm 0,9$ & $22,8 \pm 0,7$ \\
\hline
\end{tabular}

* Ni $=N$ ingéré en $g$.

Les quantités de $\mathrm{N}-\mathrm{NH}_{3}$ présentes dans la panse I heure après le repas (calculées d'après le volume du contenu de cet organe), sont similaires pour l'ensilage préfané et le foin et plus faibles pour l'ensilage AIV (tabl. 7).

\section{TABLEAU 7}

Quantités totales de $\mathrm{N}-\mathrm{NH}_{3}$ et de $\mathrm{N}$ non protéique trouvées dans le rumen 1 heure après le repas du matin

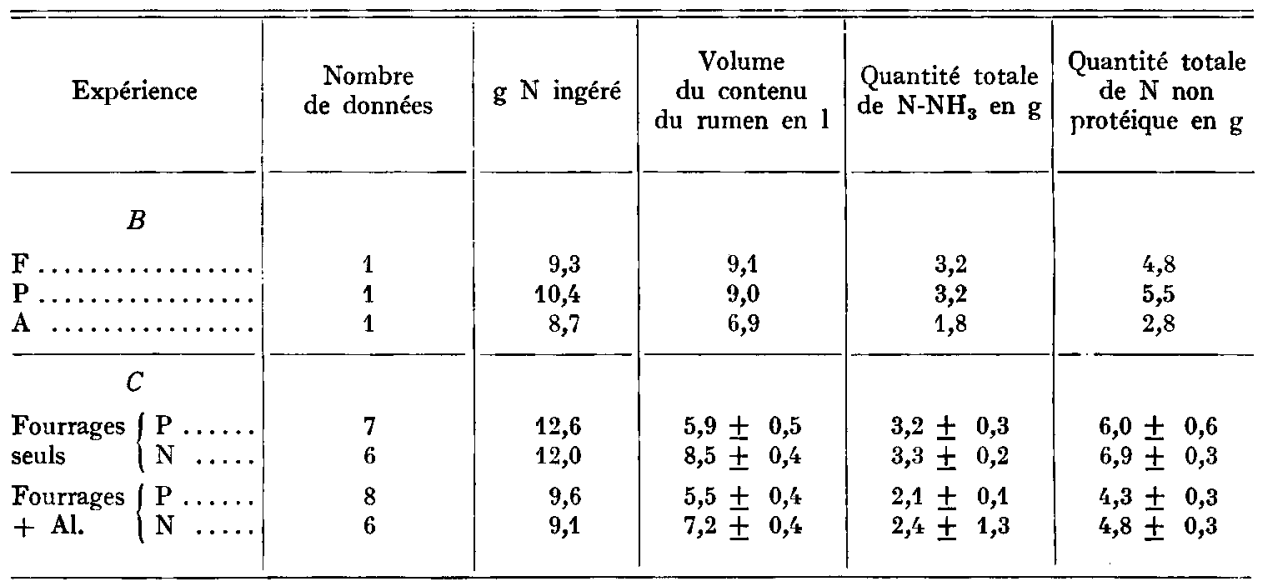

$F=$ foin ventilé

$\mathbf{P}=$ ensilage préfané

A $=$ ensilage AIV

$\mathrm{N}=$ ensilage humide non traité

$\mathrm{Al}=$ aliment aggloméré énergétique. 
L'urémie est plus élevée avec le régime foin qu'avec les ensilages. La différence est particulièrement nette pour les animaux en bilan azoté (tabl. 6). Chez ces mêmes sujets, l'ensilage AIV, malgré un ingéré azoté supérieur, donne des concentrations en urée sanguine voisines de celles de l'ensilage préfané.

\section{Digestibilité et rétention azotée.}

Les rations étant établies sur un apport équivalent de matière sèche, les ingesta de $\mathrm{N}$ et de MOD sont sensiblement inférieurs pour les ensilages préfanés et le foin (tabl. 4), que pour l'ensilage AIV plus riche en matière organique digestible et en matières azotées (tabl. 3 ).

Les coefficients de digestibilité azotée apparent et réel de ce dernier sont nettement supérieurs $(\mathrm{P}<\mathrm{O}, \mathrm{I})$ à ceux $\mathrm{du}$ foin et surtout de l'ensilage préfané qui a chauffé (tabl. 4).

Les bilans azotés sont positifs pour les trois régimes. Les coefficients de rétention ont tendance à être supérieurs pour l'ensilage AIV, mais les différences ne sont pas significatives.

\section{$3^{0}$ Comparaison entre ensilages humides non traités et préfanés donnés seuls ou en régime mixte \\ Expérience $C$}

L'ensilage préfané à $4^{\circ} \mathrm{p}$. Ioo de matière sèche est de bonne qualité. L'ensilage humide non traité est moins bien conservé, mais sa qualité est supérieure à celle escomptée et à celle de l'ensilage traité au métabisulfite de sodium, de l'expérience $\mathrm{A}$ (tabl. 3).

\section{Ammoniogenèse dans le rumen et urémie périphérique.}

En régime fourrage seul, l'ensilage préfané entraîne dans la panse une plus forte élévation des concentrations en $\mathrm{N}$ non protéique et $\mathrm{N}-\mathrm{NH}_{3}$ que l'ensilage humide et ce, quel que soit le mode d'expression des résultats (fig. 3 et 4 ). Les concentrations d'urée sanguine sont de même plus élevées avec le premier (fig. 3).

Les valeurs de $\mathrm{N}-\mathrm{NH}_{3}$ et de $\mathrm{N}$ non protéique dans le rumen atteignent leur maximum environ $\mathrm{I}$ à 2 heures après le début du repas et celles d'urée sanguine 2 à 3 heures après celles de $\mathrm{N}-\mathrm{NH}_{3}$.

Le volume du contenu du rumen I heure après le repas étant significativement plus faible avec les régimes d'ensilage préfané, les quantités totales de $\mathrm{N}-\mathrm{NH}_{3}$ et de $\mathrm{N}$ non protéique présentes alors (calculées d'après le volume) sont identiques pour les 2 ensilages (tabl. 7).

En régime mixte, la dilution azotée de l'ensilage par l'aliment énergétique, diminue l'ampleur de l'ammoniogenèse et abaisse les concentrations de $\mathrm{N}$ non protéique dans le rumen. Ce phénomène est net, même lorsque 1'accroissement des concentrations ammoniacales est rapporté à l'azote ingéré (fig. 4). Parallèlement, les quantités totales de $\mathrm{N}-\mathrm{NH}_{3}$ et $\mathrm{N}$ non protéique observées I heure après le repas et l'urée sanguine périphérique sont plus basses. 


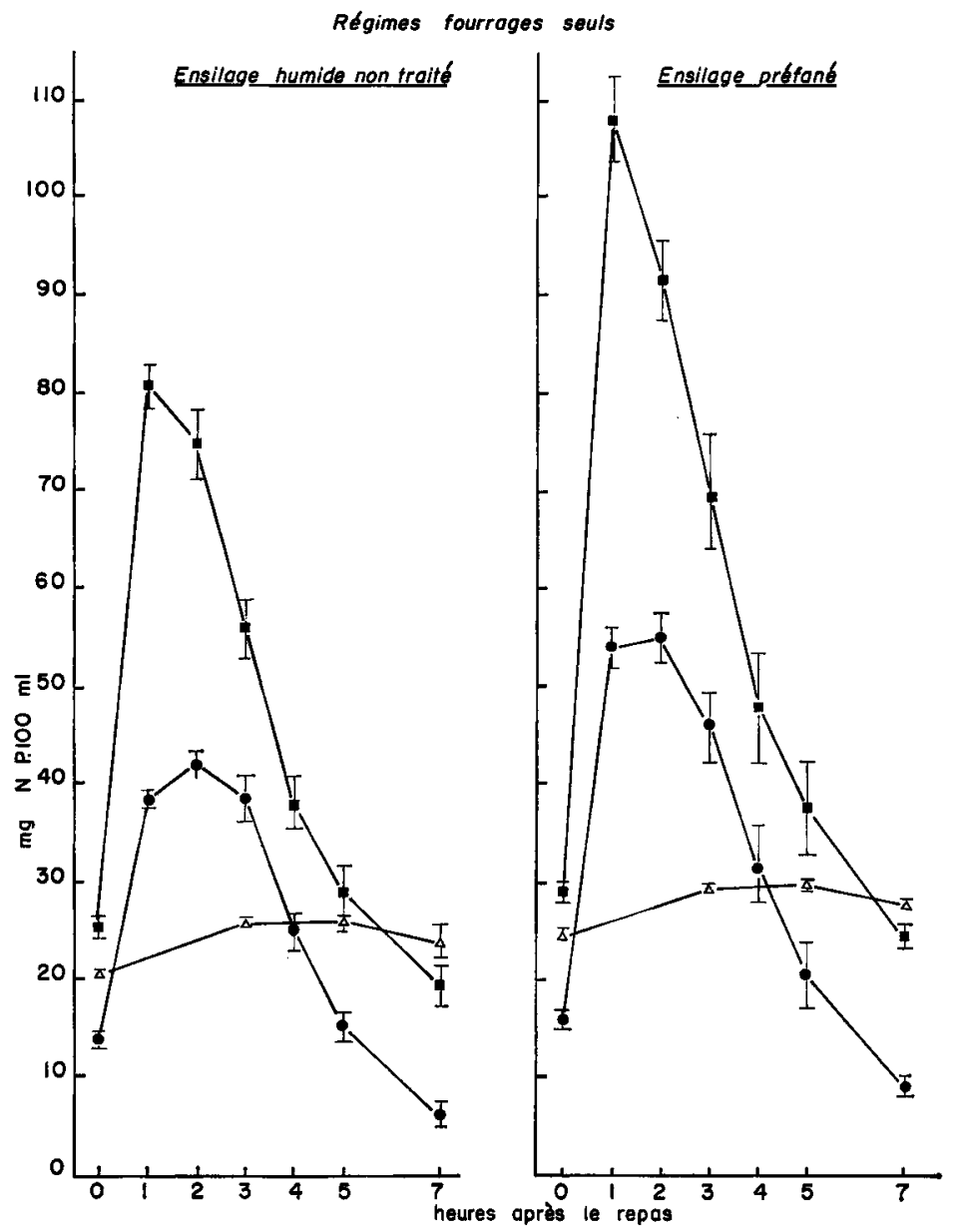

Fig. 3a-. - Expérience $C$

Evolution de $N-N_{3}, N$ non protéique dans le rumen et de $N$ urée du sang périphérique (mg $\mathrm{N} \mathrm{p.} 100 \mathrm{ml}$ )

$$
\begin{aligned}
& -\bullet-\mathrm{N}-\mathrm{NH}_{3} \\
& --\mathrm{N} \text { non protéique } \\
& -\Delta-\frac{\mathrm{N}}{\bar{c}} \text { urée sanguine } \\
& \mathrm{I}
\end{aligned}
$$

Régimes fourrages seuls $\mathrm{g} \mathrm{N}$ ingéré ensilage humide $12,0 \pm 0,5$ ensilage préfané I2,6 $\pm 0,6$

Régimes mixtes ensilage humide $9, \mathbf{I} \pm 0,6$ ensilage préfané $9,6 \pm 0,6$ 
Régimes mixtes
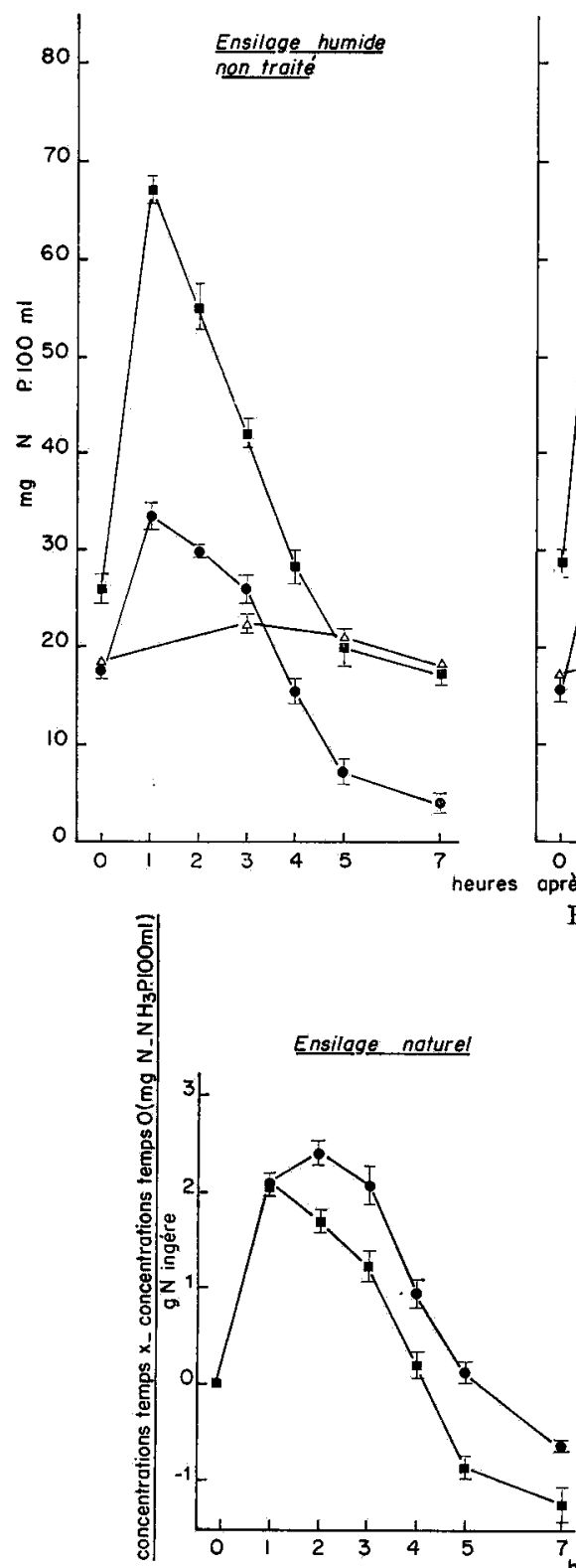

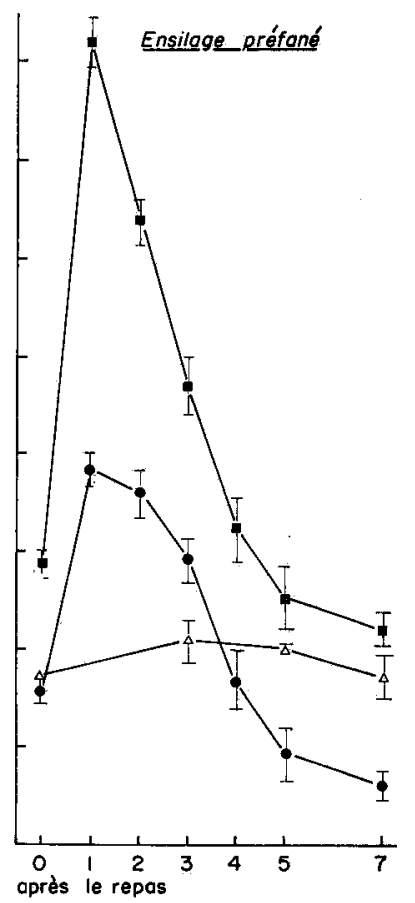

FIG. $3 b$.
FIG. 3b-. - Expérience C Evaluation de $N-N_{3}$, $N$ non protéique dans le rumen et de $N$ urée du sang périphérique (mg N p. $100 \mathrm{ml}$ )

$\rightarrow \quad \mathrm{N}-\mathrm{NH}$

- $\mathrm{N}$ non protéique $-\Delta-\quad N$ urée sanguine I $\bar{x} \pm \sigma$

Régimes fourrages seuls g N ingéré ensilage humide I $2,0 \pm 0,5$ ensilage préfané I $2,6 \pm 0,6$

Régimes mixtes ensilage humide $9, \mathrm{I} \pm 0,6$

ensilage préfané $9,6 \pm 0,6$

FIG. 4. - Expérience $C$

Augmentation des concentrations de $\mathrm{N}-\mathrm{NH}_{3}$

du jus de rumen rapportée d̀ $N$ ingéré avec le repas du matin

en ordonnée : concentration temps $x-$ concentration temps $\circ$ (mg N-NH

$$
\text { g } \mathrm{N} \text { ingéré }
$$

- - régimes fourrages seuls

- régimes mixtes

I $\bar{x} \pm \sigma$ 


\section{Digestibilité et rétention azotée.}

Un animal malade (de race limousine) a đû être éliminé des deux périodes fourrage seul. Les consommations de matière organique digestible rapportées à $\mathrm{P}^{\mathbf{0} 75}$ sont assez similaires pour tous les animaux et les deux régimes. Les quantités des matières azotées ingérées, correspondent à 2,4 fois les besoins théoriques en régime fourrages seuls et $\mathrm{I}, 2$ fois en régime mixte.

En régime fourrage seul, la digestibilité azotée de l'ensilage préfané aurait tendance à être plus faible mais n'est pas significativement différente de celle de l'ensilage humide (tabl. 4).

\section{TABLEAU 8}

Résultats individuels obtenus en régime mixte Expérience $C$

\begin{tabular}{|c|c|c|c|c|c|c|c|c|c|c|c|}
\hline \multicolumn{2}{|c|}{ Animaux } & \multirow{2}{*}{ Période } & \multirow{2}{*}{$\begin{array}{l}\text { MOD Al } \\
\% \\
\text { MODT }\end{array}$} & \multirow{2}{*}{$\begin{array}{c}\text { MAD Al } \\
\% \\
\% \\
\text { MADT }\end{array}$} & \multirow{2}{*}{$\begin{array}{c}\text { Bilan } \\
\text { azoté } \mathrm{g}\end{array} \mid$} & \multirow{2}{*}{$\begin{array}{l}\text { N-uri- } \\
\text { naire } \\
\% \mathrm{~N} \\
\text { ingéré }\end{array}$} & \multicolumn{2}{|c|}{$\begin{array}{l}\text { Digestibilité } \\
\text { de } \mathbf{N}\end{array}$} & \multicolumn{3}{|c|}{ Rétention en p. 100} \\
\hline $\begin{array}{l}\text { Poids } \\
\text { vif } \mathrm{kg}\end{array}$ & Sujets & & & & & & $\operatorname{CUD}_{a}$ & CUD $_{r}$ & $\frac{\mathrm{Nda}-\mathrm{Nu}}{\mathrm{Ni}}$ & $\frac{\mathrm{Nda}-\mathrm{Nu}}{\mathrm{Nda}}$ & $\frac{N d v-N u}{N d v}$ \\
\hline \multirow{2}{*}{40} & $\begin{array}{l}1 \\
2\end{array}$ & $\mathbf{P}$ & 62 & 26 & $\begin{array}{l}+2,2 \\
+\quad 2,8\end{array}$ & $\begin{array}{l}49,7 \\
42,3\end{array}$ & $\begin{array}{l}64,1 \\
61,1\end{array}$ & $\begin{array}{l}89,9 \\
84,1\end{array}$ & $\begin{array}{l}14,2 \\
18,9\end{array}$ & $\begin{array}{l}22,1 \\
31,0\end{array}$ & $\begin{array}{l}42,5 \\
49,8\end{array}$ \\
\hline & $\begin{array}{l}1 \\
2\end{array}$ & $\mathrm{~N}$ & 62 & 26 & $\begin{array}{l}+2,9 \\
+2,7\end{array}$ & $\begin{array}{l}44,0 \\
50,0\end{array}$ & $\begin{array}{l}62,7 \\
67,2\end{array}$ & $\begin{array}{l}85,4 \\
89,6\end{array}$ & $\begin{array}{l}18,8 \\
17,2\end{array}$ & $\begin{array}{l}30,0 \\
25,6\end{array}$ & $\begin{array}{l}48,6 \\
44,2\end{array}$ \\
\hline \multirow{2}{*}{60} & $\begin{array}{l}3 \\
4\end{array}$ & $\mathbf{P}$ & 48 & 18 & $\begin{array}{l}+\quad 0,1 \\
+\quad 2,7\end{array}$ & $\begin{array}{l}67,8 \\
53,1\end{array}$ & $\begin{array}{l}68,3 \\
65,9\end{array}$ & $\begin{array}{l}88,5 \\
86,1\end{array}$ & $\begin{array}{r}0,4 \\
12,7\end{array}$ & $\begin{array}{r}0,7 \\
19,3\end{array}$ & $\begin{array}{l}23,2 \\
38,2\end{array}$ \\
\hline & $\begin{array}{l}3 \\
4\end{array}$ & $\mathrm{~N}$ & 48 & 18 & $\begin{array}{l}+1,1 \\
+2,3\end{array}$ & $\begin{array}{l}65,6 \\
59,1\end{array}$ & $\begin{array}{l}70,7 \\
70,0\end{array}$ & $\begin{array}{l}90,5 \\
90,5\end{array}$ & $\begin{array}{r}5,2 \\
10,9\end{array}$ & $\begin{array}{r}7,3 \\
15,5\end{array}$ & $\begin{array}{l}27,6 \\
34,6\end{array}$ \\
\hline
\end{tabular}

$\mathbf{P}=$ ensilage préfané

$\mathrm{N}=$ ensilage humide non traité

MOD = matière organique digestible

MAD = matière azotée digestible

Al = aliment aggloméré

En régime mixte, l'adjonction de l'aliment énergétique, — dont le propre coefficient de digestibilité apparente $\left(\mathrm{CUD}_{a}\right)$ de 1'azote mesuré sur 2 animaux est de 47,8 p. roo, - abaisse le coefficient apparent de digestibilité du régime d'une dizaine de points. Ce résultat prévisible est d'autant plus net que la proportion de cet aliment dans la ration est plus élevée (tabl. 8). Le $\mathrm{CUD}_{a}$ de l'azote de l'ensilage humide distribué est de $76, x$, il tombe en régime mixte à 70,3 pour les animaux de $60 \mathrm{~kg}$ dont la ration contient 48,5 p. Ioo de MS d'aliment énergétique et à 64,9 pour ceux de $40 \mathrm{~kg}$ qui en reçoivent $6 \mathrm{I}, 6 \mathrm{p}$. Ioo.

Les légères différences de digestibilités apparentes observées entre ensilages en régime fourrages seuls semblent persister en régime mixte. Les coefficients de digestibilité réelle sont par contre semblables pour tous les régimes. 
En régime fourrage seul, les bilans azotés relevés pour l'ensilage préfané, sont toujours supérieurs à $+\mathrm{I} \mathrm{gN} / \mathrm{jour}(+3,5 ;+\mathrm{I}, \mathrm{I} ;+\mathrm{I}, 9)$. Avecl'ensilage humide ils sont très hétérogènes $(-3,5 ;+3,6 ;+0,7)$. Les coefficients de rétention, quel que soit leur mode de formulation sont toujours beaucoup plus faibles pour 1'ensilage humide; mais en raison de fortes variations individuelles, les différences ne sont pas significatives.

En régime mixte, quel que soit l'ensilage, tous les bilans azotés sont positifs (tabl. 8) : ils dépassent toujours $+2 \mathrm{~g} \mathrm{~N} /$ jour pour les animaux de $40 \mathrm{~kg}$, recevant la plus forte proportion d'aliment complémentaire. Les coefficients de rétention azotée deviennent identiques pour les deux ensilages et sont plus élevés qu'en régime fourrage seul ; le phénomène est plus accentué chez les animaux de $40 \mathrm{~kg}$ que chez ceux de $60 \mathrm{~kg}$ (différence de I5 points entre les deux groupes d'animaux) (tabl. 8 ).

\section{DISCUSSION E'T CONCLUSION}

Le nombre de données que nous avons obtenues à l'intérieur de chaque expérience est parfois insuffisant pour avoir des résultats significatifs. En particulier les animaux porteurs de fistules, plus fragiles que les animaux intacts, sont plus difficiles à maintenir en cage à métabolisme pendant de longues périodes, ce qui nous a conduit parfois à en supprimer en cours d'expérience.

Toutefois, en reprenant d'une part l'ensemble des résultats de nos trois expériences, avec les régimes fourrages seuls, d'autre part ceux obtenus au laboratoire en régimes mixtes par nous-mêmes sur la coupe de luzerne de l'année 64 et par SHINN sur les coupes des années I96I et I962, il est possible de dégager certaines différences caractéristiques dans l'utilisation azotée des fourrages suivant la technique de conservation et le mode de distribution du fourrage conservé.

\section{A - Régimes fourrages seuls}

\section{I' Relation entre intensité d'ammoniogenèse au niveau du rumen et concentration d'urée sanguine.}

Quelques-uns des résultats précédents concernant les mesures au niveau du rumen sont délicats à interpréter ; en effet pour pouvoir comparer l'influence des régimes sur l'ammoniogenèse, de nombreuses conditions expérimentales devraient être strictement identiques : parmi celles-ci citons les quantités d'azote et d'eau ingérées, la durée du repas d'épreuve ; cela est difficilement réalisable avec des fourrages conservés dont la teneur en matière sèche et l'appétibilité varient en fonction du traitement.

D'une façon générale, l'hypothèse, selon laquelle des ensilages qui renferment une forte proportion de matière azotée soluble ( $>$ à $70 \mathrm{p}$. I00 $\mathrm{N}$ total) donnent lieu à une importante ammoniogenèse, se trouve confirmée. Ce phénomène est observé même avec l'ensilage préfané qui est d'excellente qualité : les quantités d'ammoniaque contenues dans le rumen $I$ heure après le repas sont identiques avec cet ensilage et l'ensilage humide (tabl. 7). 
Le foin contenant moins de $50 \mathrm{p}$. Ioo d'azote total sous forme soluble, il est normal que les accroissements des concentrations ammoniacales par rapport au taux initial dans le rumen soient nettement moins importantes qu'avec les ensilages. En revanche, les concentrations initiales (avant le repas) sont souvent plus élevées avec le foin qu'avec l'ensilage préfané. Ce phénomène ne serait pas dû à une différence de volume de contenu de rumen d'après les résultats de l'expérience $\mathbf{B}$ (tabl. 7) ; mais peut-être à une dégradation plus lente de l'aliment ou à un retour d'urée plus important dans le rumen.

Avec les ensilages de l'expérience $C$, les taux les plus élevés d'urée sanguine, correspondent aux plus fortes concentrations de $\mathrm{NH}_{3}$ dans le rumen ce qui a aussi été observé par LEWIS (I957) et TAGARI, AsCAREILI et BONDI (I964) pour des aliments différents. Mais contrairement à ces auteurs et à CHALMERS et MARSHALL (I964) nous ne trouvons pas de relation entre les concentrations ammoniacales dans le rumen celles d'urée sanguine et l'excrétion azotée urinaire absolue: avec l'ensilage préfané, des concentrations maximales de $55 \mathrm{mg}$ de $\mathrm{N}-\mathrm{NH}_{3} \mathrm{p}$. Ioo $\mathrm{ml}$ dans le rumen et de $28 \mathrm{mg}$ de $\mathrm{N}$-uréique p. Ioo $\mathrm{ml}$ dans le sang, correspondent à une excrétion azotée urinaire de $2 \mathrm{I}$ g/jour ; avec l'ensilage humide des teneurs maximum de $42 \mathrm{mg} \mathrm{N}-\mathrm{NH}_{3}$ p. Ioo $\mathrm{ml}$ dans le rumen et $25 \mathrm{mg} \mathrm{N}$-uréique $\mathrm{p}$. Ioo $\mathrm{ml}$ dans le sang, correspondent à une excrétion azotée urinaire de $25 \mathrm{~g} /$ jour, pour des ingérés azotés voisins.

\section{$2^{\circ}$ Digestibilité azotée.}

Les coefficients de digestibilité des ensilages humides quel que soit leur traitement, sont significativement supérieurs $(\mathrm{P}<0, \mathrm{OI})$ à ceux du foin et de 1'ensilage préfané $\left(\mathrm{CUD}_{a}\right.$ moyen des premiers $=75,0 \pm 0,3$ contre $73, \mathrm{I} \pm 0,5$ pour les seconds (tab1. 4). La digestibilité plus élevée de 1'azote des ensilages mal conservés s'explique aisément par leur plus forte teneur en formes azotées simples, résorbées en totalité au niveau du tube digestif. Dans ce cas les coefficients de digestibilité sont sans rapport avec la valeur azotée puisque les coefficients correspondants de rétention azotée sont les plus faibles. Ces résultats sont bien en accord avec ceux de SHINN (I963) et de FERRANDo (I966). La digestibilité élevée de l'ensilage AIV (expérience B), dont les protéines se sont très peu dégradées au cours de l'ensilage, pourrait être due à un autre phénomène : influence $\mathrm{du} \mathrm{pH}$ acide (?), absence d'échauffement lors de la conservation. Par contre, la faible digestibilité azotée de 1'ensilage préfané de cette même expérience est vraisemblement imputable à une fermentation chaude.

\section{$3^{\circ}$ Efficacité azotée.}

L'ensilage le moins bien conservé (ensilage au métabisulfite de l'expérience A) est le seul à entraîner des bilans azotés négatifs ; étant moins bien consommé du fait de son inappétence son apport énergétique ne représente que $80 \mathrm{p}$. Ioo des besoins théoriques. Ce qui pourrait expliquer l'importance de l'excrétion azotée urinaire (82 p. Ioo du $\mathrm{N}$ ingéré), la matière azotée étant dans ce cas utilisée à des fins énergétiques. Cependant pour les régimes foin et ensilage préfané de l'expérience $B$ dont les niveaux énergétiques sont similaires et de l'ordre de 80 p. Ioo des normes, (tabl. 4, ingesta de MOD) les bilans azotés sont systématiquement positifs. Aussi on est conduit à 
penser que les bilans azotés négatifs de l'ensilage au métabisulfite n'ont pas tant pour origine la carence énergétique que la qualité de l'ensilage. Des bilans azotés négatifs après consommation de mauvais ensilages sont aussi relevés par FERRANDo (I966) sur moutons, et par CONRAD et $a l$., (I96I) sur vaches laitières.

Les écarts individuels sont généralement plus réduits quand les valeurs sont exprimées en rétention réelle (correction pour $\mathbf{N}$ fécal métabolique). Ces valeurs sont très voisines pour les ensilages préfanés des 3 expériences : l'erreur-type de l'ensemble des données ne représente que $5 \mathrm{p}$. roo de la moyenne (tab1. 9). Les coefficients sont similaires à ceux du vert congelé du foin et de l'ensilage AIV. Par contre,

\section{TABLEAU 9}

Régimes fourrages seuls.

Influence comparée des ensilages préfanés et des ensilages directs non acidifiés sur les coefficients de rétention azotée

(moyenne de l'ensemble \pm erreur type)

\begin{tabular}{|c|c|c|c|c|c|}
\hline & \multirow{2}{*}{$\begin{array}{l}\text { Nombre } \\
\text { de données }\end{array}$} & \multirow{2}{*}{$\begin{array}{l}\text { Azote ingéré } \\
\mathrm{g} / \mathrm{kg} \mathrm{P}^{\mathbf{0}, 75}\end{array}$} & \multirow{2}{*}{$\begin{array}{l}\text { MOD ingérée } \\
\mathrm{g} / \mathrm{kg} \mathbf{P}^{\mathbf{0}, 75}\end{array}$} & \multicolumn{2}{|c|}{ Rétention ou pertes $\%$} \\
\hline & & & & $\frac{\mathrm{Nda}-\mathrm{Nu}}{\mathrm{Ni}}$ & $\frac{\mathrm{Ndr}-\mathrm{Nu}}{\mathrm{Ndr}}$ \\
\hline $\begin{array}{l}\text { Ensilages préfanés ........ } \\
\text { Ensilages directs non aci- } \\
\quad \text { difiés } \ldots \ldots \ldots \ldots \ldots \ldots\end{array}$ & $\begin{array}{r}11 \\
7\end{array}$ & $\begin{array}{l}1,33 \pm 0,07 \\
1,42 \pm 0,09\end{array}$ & $\begin{array}{l}24,5 \pm 1,3 \\
25,7 \pm 2,4\end{array}$ & $\mid \begin{array}{c}26,2 \pm 1,2^{* *} \\
-2,4 \pm 3,1\end{array}$ & $\begin{array}{l}22,7 \pm 1,2 * * \\
10,9 \pm 3,8\end{array}$ \\
\hline
\end{tabular}

** Différences ensilages préfanés $\times$ ensilages directs significatives au seuil $P<0,01$.

les coefficients de rétention des ensilages humides non acidifiés sont significativement plus faibles ( $\mathrm{P}<0,0 \mathrm{I}$ ) (tabl. 9). Récemment WaLDo et al., (I965) trouvent de même avec un ensilage humide de luzerne de qualité médiocre consommé ad libitum par des bouvillons, des coefficients de rétention azotée inférieurs à ceux du foin correspondant. La plus faible efficacité azotée des ensilages humides mal conservés peut être a priori reliée à l'état plus dégradé de leurs matières azotées (tabl. 3, exp. A). Cependant les proportions de $\mathrm{N}$ soluble et de $\mathrm{N}$ non protéique sont assez voisines dans les ensilages préfanés et et les ensilages humides non acidifiés. Mais FAtianoff et al., (I966) enregistrent pour les fourrages de l'expérience A des pertes de lysine beaucoup plus élevées dans l'ensilage au métabisulfite que dans les ensilages préfanés et AIV correspondants : les taux respectifs de $\mathrm{N}$ lysine $\mathrm{p}$. Ioo $\mathrm{N}$ total sont de $2,8,5,2$ et 6,6 alors que la luzerne verte ( $2^{\mathrm{e}}$ coupe I963) qui a servi à la fabrication de ces ensilages en contenait 7,4 p. 100 à la mise en silo.

La richesse en lysine des ensilages préfanés n'est probablement ni la plus satisfaisante ni la seule explication de leur efficacité azotée élevée. Cet acide aminé peut être catabolisé rapidement dans le rumen par les bactéries LEwIs et EMERY, (I962) et après un repas d'ensilage préfané la rapidité et l'intensité des l'ammoniogenèse 
dans le rumen sont, comme nous l'avons déjà signalé, aussi fortes qu'avec un ensilage humide. Cela conduit à penser que la supériorité des ensilages préfanés pourrait tenir en partie du moins à sa teneur en certains métabolites, qui favoriseraient la protéo-synthèse microbienne dans le rumen à partir du $\mathrm{NH}_{3}$ formé $i n$ situ.

En retardant et en réduisant l'ampleur des fermentations dans l'ensilage, le préfanage, préserve certains constituants, notamment des glucides Gover et al., (I965). Ainsi dans l'expérience $\mathrm{C}$, la matière sèche de l'ensilage préfané renferme $2,3 \mathrm{p}$. Ioo de glucides solubles résiduels, contre $0,2 \mathrm{p}$. Ioo seulement dans l'ensilage humide ; ces teneurs sont identiques à celles citées par WALDo et al., (I965) pour les mêmes types d'ensilage $(2,5 \mathrm{p}$. Ioo MS contre $0,2 \mathrm{p}$. IOo). Ces oses sont très rapidement métabolisées par les bactéries du rumen : $80 \%$ des glucides solubles du trèfle disparaissent du rumen à la fin du repas et la totalité en 3 heures BAILEY (I965). D'autres facteurs qu'il y aurait lieu de rechercher dans ce type d'ensilage pourraient aussi activer la protéosynthèse bactérienne : hemicelluloses, substances pectiques, acides gras ramifiés à courte chaîne, ou même oligopeptides qui contrairement aux acides aminés libres peuvent être d'excellentes sources d'azote pour Bactéroïdes ruminicola PitTman et Bryan's, (Ig64). Selon Hoshino et Sarumaru (I966), un autre processus dont on ne connaît pas l'importance quantitative pourrait intervenir dans l'utilisation du $\mathrm{NH}_{3}$ : la formation de glutamine à partir d'acide glutamique dans la paroi du rumen. Nous avons pu constater que l'acide glutamique libre n'était pas catabolisé dans un ensilage préfané alors qu'il l'était rapidement avec formation d'acide $\gamma$-aminobutyrique dans un ensilage humide non traité GoueT et al., ( 1965$)$. Ce processus de fixation de 1'ammoniaque pourrait ainsi plus facilement avoir lieu dans les ensilages préfanés.

\section{$\mathrm{B}$ - Régimes mixtes}

\section{Io Intensité de l'ammoniogenèse au niveau du rumen.}

Il semblerait que, la distribution simultanée de l'aliment énergétique et de l'ensilage ait pour effet de diminuer l'ampleur de l'ammoniogenèse, sans que le phénomène soit dû uniquement à une différence dans les ingesta azotés (fig. 4). Il est difficile de savoir si cela témoigne d'une moindre désamination ou d'une protéosynthèse bactérienne accrue au niveau du rumen. Des faits similaires sont enregistrés, en particulier par Annison et al (r954) après addition d'amidon.

\section{$2^{\circ}$ Digestibilité azotée.}

Les régimes fourrages seuls et les régimes mixtes ont des coefficients réels de digestibilité de l'azote similaires. Par contre, il y a une différence nette dans les coefficients de digestibilité apparents : une chute de so points environ en régime mixte par rapport aux régimes fourrages seuls. Ce fait n'est sans doute pas dû̀ à l'abaissement de la teneur en matière azotée totale qui passe de $18 \mathrm{p}$. Ioo en régime fourrage seul, à I $2 \mathrm{p}$. Ioo en régime mixte, mais plutôt à la moindre digestibilité azotée de l'aliment aggloméré, dont le $\mathrm{CUD}_{a}$ mesuré par ailleurs n'est que de 47,8 p. roo. Compte tenu des différentes proportions de cet aliment et d'ensilage reçu par les deux lots d'animaux le calcul théorique de la digestibilité apparente des rations mixtes donne des valeurs assez voisines de celles observées (tabl. Io). 


\section{TABLEAU IO}

Digestibilité apparente de $N$ en régime mixte. Expérience $C$

\begin{tabular}{|c|c|c|c|}
\hline \multirow{2}{*}{ Poids des animaux } & \multirow{2}{*}{ Régimes } & \multicolumn{2}{|c|}{ CUDa } \\
\hline & & calculés * & mesurés \\
\hline \multirow{2}{*}{$40 \mathrm{~kg}$} & $\mathrm{P}$ & 64,8 & $62,6 \pm 1,5$ \\
\hline & $\mathrm{N}$ & 65,8 & $64,9 \pm 2,3$ \\
\hline \multirow{2}{*}{$60 \mathrm{~kg}$} & $\mathrm{P}$ & 67,7 & $67,1 \pm 1,2$ \\
\hline & $\mathrm{N}$ & 68,8 & $70,3 \pm 0,3$ \\
\hline
\end{tabular}

* Calculés en tenant compte de la digestibilité intrinsèque de l'aliment aggloméré $(47,8$ p. 100$)$ et des différentes proportions aliment, ensilages.

$\mathrm{P}=$ Ensilage préfané.

$\mathbf{N}=$ Ensilage humide non traité.

\section{TABLEAU II}

Influence de la technique de conservation sur l'efficacité azotée de la luzerne en régimes mixtes.

(moyennes des résultats 196r-1962-1964)

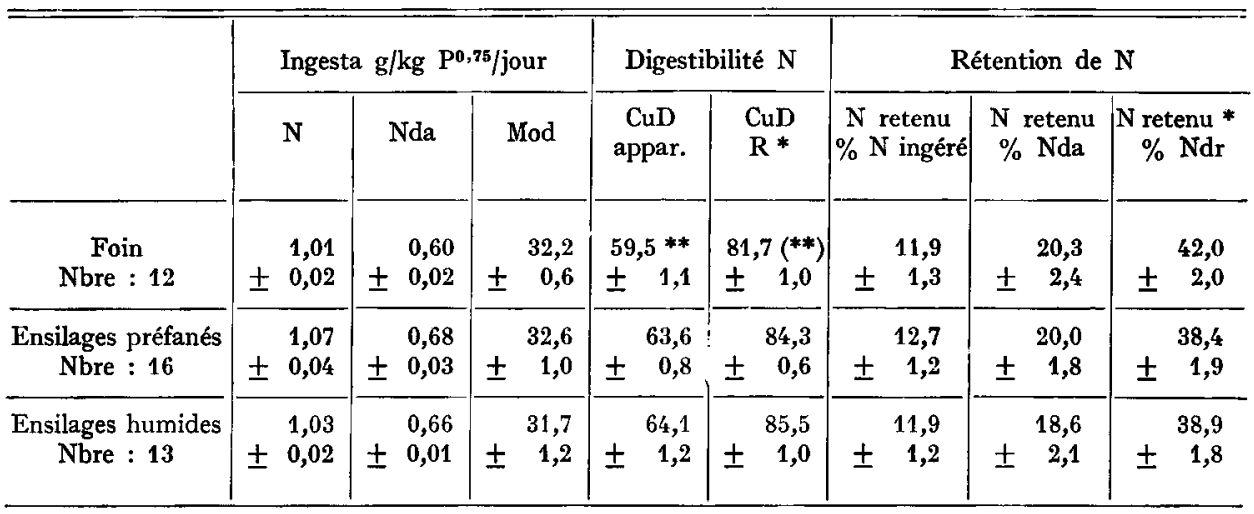

* Correction pour $\mathrm{N}$ fécal métabolique : $0,4 \mathrm{~g} \mathrm{~N}$ p. $100 \mathrm{M} . \mathrm{S}$. ingérée.

** Différences Foin-Ensilages significatives au seuil $\mathrm{P}<0,01$. 
Bien qu'en régime mixte les $\mathrm{CUD}_{a}$ soient plus faibles, les différences relevées en régimes fourrages seuls persistent. Pour l'ensemble des résultats obtenus en régime mixte par SHrnN (I963) et nous-mêmes (tabl. II), le foin a une digestibilité significativement plus faible que les ensilages quels qu'ils soient.

\section{$3^{\circ}$ Efficacité azotée.}

La dilution des ensilages par l'aliment énergétique a pour effet d'augmenter le bilan azoté de l'ensilage humide et d'améliorer les coefficients de rétention par rapport aux régimes ensilages seuls. Des résultats analogues sont relevés par d'autres auteurs, qui distribuent avec des ensilages divers, des aliments énergétiques : CoNRAD et al. (I96r) améliorent l'utilisation azotée du régime par des vaches laitières en distribuant du grain avec l'ensilage ; FERRANDo (Ig66) rétablit chez le mouton des bilans azotés positifs, en ajoutant de la fécule de pomme de terre aux rations d'ensilage. Dans notre expérience de régime mixte, la différence d'utilisation azotée entre ensilage humide et préfané s'estompe totalement. Il en est de même dans celle de SHINv ; même un ensilage très mal conservé contenant 27,6 p. Ioo d'azote total à l'état de $\mathrm{N}-\mathrm{NH}_{3}$, et 2,3 p. roo de M.S. sous forme d'acide butyrique, donne des bilans azotés positifs et un coefficient de rétention vraie $(38 \mathrm{p}$. 10o) similaire à ceux des bons ensilages préfanés. Sur l'ensemble des valeurs observées en régime mixte par nous-mêmes et par ShINN (tabl. II), il n'y a pas de différence significative dans les rétentions azotées des foins, des ensilages humides et des ensilages préfanés de luzerne.

Tout se passe donc comme si les glucides apportés par les pulpes sèches de 1'aliment complémentaire de notre expérience $C$, ou l'amigel et le cérélose de l'aliment utilisé par SHINN, aient favorisé la protéosynthèse bactérienne au niveau du rumen, masquant de la sorte la valeur azotée intrinsèque des fourrages conservés. On ne peut cependant exclure a priori des effets métaboliques en d'autres lieux (par exemple au niveau systémique dans divers tissus).

La technique de conservation par préfanage est, au plan technologique, sans aucun doute aussi efficace que la technique aux acides AIV. Dans des conditions climatique adéquates, son application est aisée et peu onéreuse. Du point de vue nutritionnel, elle offre, outre l'avantage de favoriser la consommation de matière sèche d'ensilage, celui d'améliorer nettement l'efficacité de l'azote de la luzerne ensilée et de la rendre comparable à celle du vert et d'un bon foin correspondant (dans la mesure où nos résultats sur animaux adultes à l'entretien, se trouveraient confirmés sur des animaux en production).

Les ensilages humides non acidifiés subissent en règle générale des catabolismes glucidiques et azotés intenses, ce qui amoindrit fortement leur valeur azotée au point d'entraîner parfois des bilans azotés négatifs même lorsque l'ingéré azoté dépasse largement les besoins théoriques du sujet. Il est néanmoins possible d'y remédier par une distribution simultanée d'un aliment énergétique (céréales, pulpes sèches de betteraves, marcs secs de pomme etc.) susceptible d'activer la protéosynthèse bactérienne dans le rumen à partir des formes azotées particulièrement dégradées $\left(\mathrm{NH}_{3}\right)$, apportées ou engendrées par ce type d'ensilage.

Reçu pour publication en novembre 1967.

Annales de Biologie animale. - 1968. 


\section{SUMMARY}

\section{INFLUENCE OF STORAGE TECHNIQUES ON THE NITROGEN EFFICIENCY OF LUCERN IN THE SHEEP}

From 1963 to 1965 , feeding experiments were conducted on adult sheep at the maintenance level, some of them being rumen-fistulates, in order to compare the nitrogen efficiency of lucern stored using various techniques : green frozen forage, barn dried hay, direct-cut silage either free from additive or added sodium metabisulfite or acidified by the A I V process, wilted silage at 35 to 40 p. I00 D. M. level. source.

For a given experiment, all processes were applied at the same day to forage lots from the same

The biological criteria were : post prandial evolution of ammonia and total non protein nitrogen concentrations in the rumen; peripheral blood urea, nitrogen balance and digestibility.

The results were the following :

- The nitrogen efficiency of lucern silage was improved by wilting, and was at the same level eicher for wilted silage or green frozen lucern or hay harvested from the same source (table 4 ).

- Glucid and nitrogen catabolisms occuring in the direct-cut unacidified lucern silage, induced a sharp decrease in the nitrogen value of the forage. In some cases, it induced negative nitrogen balances, even when the nitrogen intake was much higher than the requirements of the animal (tables 4 and 9 ).

- The intake of an energetic food which increases the bacterial utilization of the soluble nitrogen for proteosynthesis, together with a low quality silage, considerably improved the nitrogen efficiency of the latter.

\section{RÉFÉRENCES BIBL,IOGRAPHIQUES}

Annison E., Chalmers M. I., Marshall S. B. M., Synger L. M., I964. Ruminal ammonia formation with various diets. J. Agric. Sci., 44, 270-273.

Bailey R. W., I965. The digestion of insoluble carbohydrates in the reticulo-rumen. Proc. Nero Zealand. Soc. Anim. Prod., 25, 85-95.

Chalmers M. I., Marshall S. B. M., I964. Ruminal ammonia formation in relation to the utilization of groundnut meal and herring meal as protein sources for milk production. J. Agric. Sci., 63, 77-282.

Conrad H. R., Hibbs J. W., PratT A. D., Davis R. R., ig6r. Nitrogen metabolism in dairy cattle. I. The influence of grain and meadow crops harvested as hay, silage or soilage on the efficiency of nitrogen utilization. J. Dairy Sci., 44, 85-95.

Conway E. J., 1950. Microdiffusion and volumetric error. $3^{\mathrm{e}}$ éd. 95-97. Crosby Lockwood and Son Ltd. London.

Durand-Salomon M., Zelter S. Z., I960. L'évolution des catabolismes glucidique et protidique dans une luzerne ensilée: action des traitements A. I. V. et métabisulfite de sodium. Proc. 8th Internat. Grassl. Congr., Paper $3 \mathrm{~B} / 6$.

Fatianoff N., Durand M., Tisserand J. L., Zelter S. Z., 1966. The effect of wilting, mineral acidification and sodium metabisulfite on quality and nitrogen efficiency of alfalfa silages. Intern. Symp. Naturwiss. Grundlagen Silierung. Rostock.

Ferrando R., Catsaounis N., 1966. Signification de la digestibilité des matières azotées chez les ruminants Ann. Nutr. Al., 20, $127-145$.

Gouet Ph., Fatianoff N., Zelter S. Z., Durand M., Chevalier R., I965. Influence de l'élévation du taux de matière sèche sur l'évolution biochimique et bactériologique d'une luzerne conservée par ensilage. Ann. Biol. anim. Bioch. Biophys., 5, 79-100.

Hoshino S., Sarumaru K., Mormoto K., 1966. Ammonia anabolism in ruminants. J. Dairy Sci., 49, $15^{2} 3^{-1} 5^{28}$.

HYDEN S., a) 1955. A tubidimetric method for the determination of higher polyethyleneglycols in biological materials. Kung. Lantbruks. Ann., 22, I 39-I 45.

b) I96I. Determination of the amount of fluid in the reticulo rumen and its rate of passage to the omasum. Kung. Lantbruks. Annaler, 27, 5I-78.

LEROY A. M., 196r. I.e mouton, p. 65. Hachette, Paris.

LEwIS D., 1957. Blood-urea concentration in relation to protein utilization in the ruminant. J. Agric. Sci., 48, $438-446$. 
Lewis T. R., Emery R. S., I962. Metabolism of aminoacids in the bovine rumen. J. Dairy Sci., 45, I 487-I492.

Malangeau P., Bourdon R., Nicaiste A. M., Masson B. I963. Dosage des acides aminés dans les liquides de l'organisme. Ann. Biol. Clin., 21, 3-13.

Pittman K. A., Bryan'r M. P., rg64. Peptides and other nitrogen sources for growth of bacteroides ruminicoa. J. Bact., 88, 40 I -410 .

Shinn S. J., I963. Recherche critique et expérimentale concernant l'évolution de la valeur nutritionnelle de la fraction azotée d'une luzerne chez le ruminant (cas du moutor) en fonction du mode de conservation. Thèse fac. Sci. Univ. Paris. Ann. Inst. nat. agron., 1965, 3, 43-124.

Schramm G., AINEs P. O., I959. Colorimetric determination of urease activity in soybean meal. J. Amer. Oil Chem. Soc., 36, I-3.

TAgari HK., Dror Y., Ascarelli I., Bondi A., I964. The influence of levels of protein and starch in rations of sheep on the utilization of protein. Brit. J. Nutr., 18, 333-356.

Tisserand J. L., Zelter S. Z., i 965 . Essai de normalisation d'une technique de mesure de la digestion des fourrages in vilro "rumen artificiel ". Ann. Biol. anim. Biochim. Biophys., 5, IoI-I I .

Waldo D. R., Mrller R. W., OKamoto M., Moor L. A., I 965 . Ruminant utilization of silage in relation to hay, pellets, and hay plus grain. I. Composition, digestion, Nitrogen balance, Intake and growth. $J$. Dairy Sci., 48, 910-916.

Zelter S. Z., Charlet-I.́rry G., I96I. Efficacité de quelques protides alimentaires chez le porc. I. Excrétion d'azote métabolique fécal et endogène urinaire. Ann. Biol. anim. Bioch. Biophys., 1, 29-46. 